\section{Surrogacy: blessing or curse to poor society in India}

\author{
Venkatashivareddy B, ${ }^{1}$ Arti Gupta, ${ }^{1}$ \\ Viviktha Ramesh ${ }^{2}$ \\ 'Department of Community Medicine, \\ Veer Chandra Singh Garhwali \\ Government Medical Sciences and \\ Research Institute, Uttarakhand; ${ }^{2}$ Centre \\ for Community Medicine, All India \\ Institute of Medical sciences, New Delhi, \\ India
}

\begin{abstract}
The advances of childbirth in the form of test tube babies and surrogate have introduced undreamt possibilities. The reproductive tourism in India is enhancing. Globally, India is one of the popular providers of surrogates and commercial surrogacy is legalized. Moreover, the cost is a mere one third of the cost in developing countries. Surrogacy raises ethical issues like medical advocacy and consent. Many social factors like unemployment, literacy, and others play a key role in surrogacy. Surrogacy is a public health problem related not only to the medical burden but also to sex ratio deterioration, female feticide, domestic violence, and others.
\end{abstract}

\section{Introduction}

The human body is an incredibly complex and intricate system, one that wonders doctors on a regular basis. Complex biological, cultural, and psychological relations, hence reproductive health, govern reproductive behavior and rights must be understood within the context of relationships between men and women, communities and societies. The advances of childbirth in the form of test tube babies and surrogate motherhood have introduced undreamed possibilities. The literal meaning of surrogate is substitute. The word surrogate means appointed to act in the place of another. ${ }^{1}$ Surrogacy agreement is the carrying of a pregnancy for intended parents. Women who are infertile or unable to carry a pregnancy to term use this. There are three main types of surrogacy, gestational surrogacy, traditional surrogacy, and donor surrogacy. In gestational surrogacy, an egg is removed from the intended mother or an anonymous donor and fertilized with the sperm of the intended father or anonymous donor. In traditional surrogacy, a surrogate mother is artificially inseminated, by either the intended father or an anonymous donor, and carries the baby to term. In donor surrogacy, there is no genetic relationship between the child and the intended parents as the surrogate is inseminated with the sperm, not of the intended father, but of an outside donor. $^{2}$

In its quest, the paper reviews the legal, ethical, commercial and public health aspects of surrogacy in India.

\section{India as a provider}

Infertility is an emerging public health problem. This is contrasted with our conception over populated world. ${ }^{3}$ The large industry of intercontinental reproductive service provision has come mainly due to increased demand and advanced reproductive technologies from the developed world. ${ }^{4}$ Delay in starting of families by educated and working women reduces their ability to become pregnant. The rise of lifestyle disorders like obesity, diabetes has certainly contributed to infertility. ${ }^{5}$ The United States is one of the world's best provider of reproductive services. Globally, India is one of the most popular providers of reproductive services. The reproductive tourism in India is enhancing for several reasons. There is easy availability of English speaking, and highly trained doctors. There is the presence of well-developed and recognized medical tourism infrastructure, and medical care integrated travel, hotel, and insurance services. Also, lower costs of medical treatment in India attract the foreigners to utilize the benefits of medical tourism, especially surrogacy. In addition, the advantageous currency exchange rate leads to lower prices. Due to the restrictiveness of their own countries, foreigners engage in a surrogacy contract arrangement in India. Moreover, the maternal surrogacy presents an opportunity for very poor women to make easy improvements in their financial crisis. Therefore, globally increasing prevalence of infertility and enlarging poor society of India assures reproductive tourism industry continues to grow in India. ${ }^{6}$

\section{Surrogacy: legislative and financial aspects}

Law, at a particular time, represents the societal mindset and undergoes radical changes to align itself with social change. In UK and Japan, commercial surrogacy arrangements are prohibited by the surrogacy arrangement act 1985 . However, in the USA and Australia, the surrogacy legal issues fall under state jurisdiction and the situation for surrogacy differs from state to state. In Russia
Correspondence: Arti Gupta, Department of Community Medicine, Veer Chandra Singh Garhwali Government Medical Sciences and Research Institute, Distt. Pauri Garhwal, 246174 Uttarakhand, India.

Tel: +91.9412902976 .

E-mail: guptaarti2003@gmail.com

Key words: Surrogacy; Commercial; Ethics; Risk.

Conflict of interest: the authors declare no potential conflict of interest.

Contributions: VRB conceived the study; AG and VR extracted, reviewed, and synthesized the data; $\mathrm{AG}$ and VRB wrote the manuscript draft; AG, VRB and VR reviewed the manuscript; AG approved the final draft.

Received for publication: 30 July 2015 .

Accepted for publication: 13 August 2015.

This work is licensed under a Creative Commons Attribution 3.0 License (by-nc 3.0).

(C) Copyright V.B., et al., 2015

Licensee PAGEPress, Italy

Healthcare in Low-resource Settings 2015; 3:5465 doi:10.4081/hls.2015.5465

commercial surrogacy is legal, but lacks medical indication. ${ }^{7}$ Surrogacy has turned into a baffling legal quagmire and the views on its legalization have been highly divergent. Commercial surrogacy remains a controversial issue across the world. It is banned in many countries. Nevertheless, in India, the Supreme Court legalized the commercial surrogacy in 2002. ${ }^{8}$ Artificial Reproduction Technology (Regulation) Bill, 2010 requires addressing the need of legislation directly on the subject of surrogacy arrangements. Indian courts are still grappling with the issues involved in surrogacy. ${ }^{9}$ The essential elements of surrogacy are childbearing by a surrogate mother, the termination of her parental rights after his birth, and payment of money by the genetic parents. If the money paid is merely to recompense the surrogate for the pain undertaken and includes reimbursement of medical and other expenses, then it is non-commercial surrogacy. In contrast, commercial surrogacy involves payment of money as income to the surrogate for the service offered. A maternal surrogate in India is handsomely paid. ${ }^{10}$ The cost for surrogates in India as reported ranges from 2500 to 7000 US $\$$. This is a mere one third of the cost to be paid by parents in developing countries. ${ }^{11}$ Most Indian surrogate mothers are paid in installments over the antenatal period. Inability to conceive even debars them from any payment sometimes. Furthermore, sometimes they forfeit a part of their fee if they suffer miscarriage. ${ }^{12}$ 


\section{Surrogacy: ethical and social aspects}

Surrogacy raises quite profound ethical issues. The clinician is directly responsible for the medical advocacy of both the client and the surrogate. The lack of an independent medical advocate is exploitation. ${ }^{13}$ Gestational surrogacy requires in vitro fertilization, which normally involves the production of multiple embryos. Several embryos are implanted in the surrogate's womb, but the other embryos are either destroyed or frozen. The primary ethical guidelines for the frozen embryos state to treat them in a manner where there is no harm to them. ${ }^{14}$ Commercialization of surrogacy creates several social conflicts. The surrogate is often poor, uneducated, or semi-literate; this further complicates the uncertainty of true informed consent. Illiteracy is but one barrier preventing the communication of such risks. ${ }^{15}$ Women who have low-income or a lack of financial resources are typically recruited to be surrogates. Indian women are also less likely engaged in drinking alcohol or smoking, which can be detrimental to a successful pregnancy. In addition, such women are rarely fully informed about the potential health risks associated with surrogacy (e.g., hormone injections) or with the emotional damage that can come from giving up a child. Many are unaware, for example, that during pregnancy, the female body is biologically, hormonally, and emotionally programmed to bond with the child. Maternal surrogacy is where India dominates in giving her abundance of young, poor women. Economic exploitation easy for the agents working for commissioning parents, secrecy, and anonymity creates a negative environment that affects human relations. ${ }^{16}$ However, when human reproduction meets commerce, gender inequality, and wealth disparity, the potential for ethical and social transgression becomes great indeed.

\section{The public health risk of surro- gacy}

Childbirth is a natural process. Pregnancy is an innately dangerous state for a woman, especially in low-income countries. In India, surrogates are implanted with multiple embryos in order to increase the chances of pregnancy, which however increases health risk for babies and the mother. It can also harm the female donors as well as the surrogate causing multiple pregnancy, low birth weight, and malformed babies. ${ }^{17}$ Although rare, there is a small risk of ovarian hyper-stimulation syndrome, leading to abdominal pains, nausea, vomiting, breathlessness, and fainting. There is rare risk of transfer of human immunodeficiency or hepatitis virus. Ante-natal, intranatal and post-natal period inherently pose a risk of complications like pre-eclampsia and eclampsia, urinary tract infections, stress incontinence, haemorrhoids, gestational diabetes, life-threatening haemorrhage and pulmonary embolism. ${ }^{18}$ In addition, grand multiparity has been known to be an obstetric risk. The occurrence of caesarean section is also common. ${ }^{19}$ Surrogate mothers risk metabolic and circulatory complications, such as diabetes or hypertension. Death is though a small but real risk. The prevalence of anemia and malnutrition is higher in multiparity. ${ }^{20}$

Domestic violence and household strife occur on surrogate mothers due to dislikes of male partners. In addition, uncertainty exists whether the surrogate will be able to enjoy sexual relations with her husband.

These are all downstream negative consequences of the surrogacy procedure that need to be considered. Surrogacy can lead to the distortion of family relationships and society that result from breaking the marital bond in order to overcome infertility. On the other hand, the impact of surrogacy on mother-child relationships and children's psychological adjustment is undetermined. ${ }^{21}$ The demand for surrogacyrelated medical tourism interferes with ongoing healthcare services. The public sector is busy to provide advanced artificial reproductive technology rather to build basic facilities that prevent infertility. Surrogacy is also grounds for declining sex ratio and female feticide $^{22}$ and interferes with the registration system of births in the country. Increasing industry of reproductive tourism poses poor young women at a higher risk of trafficking.

\section{Conclusions}

In India surrogacy is purely a contractual understanding between the parties, so care has to be taken while drafting an agreement to avoid violation of human laws. We conclude that the Government of India should address the factors influencing surrogacy. There is an urgent call for enacting a law to regulate surrogacy in India: communication and knowledge of the medical process involved in surrogacy should be clear and open between all parties. Emotional responses occurring during the process of surrogacy should be managed with sensitivity. All parties should fairly discuss on the payment of the expenses of the surrogate by commissioning parents and should be comfortable with the surrogacy agreement. However, the birth mother has the right to manage her own pregnancy and it is no doubt that commercial surrogacy is a bane to women health in India. Hence, important legal measures should be taken.

\section{References}

1. Tuininga K. The ethics of surrogacy contracts and Nebraska's surrogacy law. Creighton Law Rev 2008;41:185-206.

2. Niekerk AV, Zyl LV. The ethics of surrogacy: women's reproductive labour. J Med Ethics 1995;21:345-9.

3. Fidler AT, Bernstein J. Infertility: from a personal to a public health problem. Public Health Rep 1999;114:494-511.

4. Bahamondes L, Makuch MY. Infertility care and the introduction of new reproductive technologies in poor resource settings. Reprod Biol Endocrin 2014;12:87.

5. Sharma R, Biedenharn KR, Fedor JM, Agarwal A. Lifestyle factors and reproductive health: taking control of your fertility. Reprod Biol Endocrin 2013;11:66.

6. Sarojini N, Marwah V, Shenoi A. Globalisation of birth markets: a case study of assisted reproductive technologies in India. Glob Health 2011;7:27.

7. Anu KP, Inder D, Sharma N. Surrogacy and women's right to health in India: issues and perspective. Indian $\mathrm{J}$ Public Health 2013;57:65-70.

8. Sreenivas K, Campo-Engelstein L. Domestic and international surrogacy laws: implications for cancer survivors. Cancer Treat Res 2010;156:135-52.

9. Parry B. Narratives of neoliberalism: 'clinical labour'. Med Hum Ser 2015;41:32-7.

10. Saxena P, Mishra A, Malik S. Surrogacy: ethical and legal issues. Indian J Commun Med 2012;37:211-3.

11. Gaur K, Garg S. Reproduction rights of women: ethical or viable role of surrogate mother. 2012;2012:2-13.

12. Ruth M. Surrogates and other mothers: the debate over assisted reproduction. Philadelphia, PA: Temple University Press; 1994.

13. Leo RJ. Competency and the capacity to make treatment decisions: a primer for primary care physicians. Prim Care Companion J Clin Psychiatry 1999;1:13141.

14. Suzuki M. In vitro fertilization in Japan. Early days of in vitro fertilization and embryo transfer and future prospects for assisted reproductive technology. P Jpn Acad B-Phys 2014;90:184-201.

15. Qadeer I. Social and ethical basis of legislation on surrogacy: need for debate. Indian J Med Ethics 2009;6:28-31.

16. Sarojini NB, Preeti A, Deepa A. Commercialisation of surrogacy in the Indian context. Available from: 
www.mfcindia.org/mfcpdfs/MFC330.pdf

17. Kondapalli LA, Perales-Puchalt A. Low birth weight: is it related to assisted reproductive technology or underlying infertility. Fertil Steril 2014;99:303-10.

18. Sharma RS. Social, ethical, medical \& legal aspects of surrogacy: an Indian sce- nario. Indian J Med Res 2014;140 (Suppl.1):13-6.

19. Jacobson B. Advanced maternal age and adverse perinatal outcome. Obstet Gynecol 2004;104:727-33.

20. Nordin NM, Fen CK, Isa S, Symonds EM. Is grandmultiparity a significant risk factor in this new millennium? Malaysian J Med Sci 2006;13:52-60.

21. van de Akker OBA. Psychosocial aspects of surrogate motherhood. Hum Reprod Update 2007;13:53-62.

22. Malpani A. Are we exploiting the infertile couple? Indian J Med Ethics 2000;8:24-5. 